\title{
Bax-inhibiting peptide protects cells from polyglutamine toxicity caused by Ku70 acetylation
}

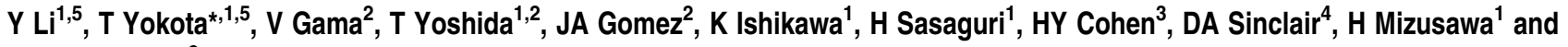 \\ S Matsuyama ${ }^{*, 2}$
}

\begin{abstract}
Polyglutamine (polyQ) diseases, such as Huntington's disease and Machado-Joseph disease (MJD), are caused by gain of toxic function of abnormally expanded polyQ tracts. Here, we show that expanded polyQ of ataxin-3 (Q79C), a gene that causes MJD, stimulates Ku70 acetylation, which in turn dissociates the proapoptotic protein Bax from Ku70, thereby promoting Bax activation and subsequent cell death. The Q79C-induced cell death was significantly blocked by Ku70 or Bax-inhibiting peptides (BIPs) designed from Ku70. Furthermore, expression of SIRT1 deacetylase and the addition of a SIRT1 agonist, resveratrol, reduced Q79C toxicity. In contrast, mimicking acetylation of Ku70 abolished the ability of Ku70 to suppress Q79C toxicity. These results indicate that Bax and Ku70 acetylation play important roles in Q79C-induced cell death, and that BIP may be useful in the development of therapeutics for polyQ diseases.
\end{abstract}

Cell Death and Differentiation (2007) 14, 2058-2067; doi:10.1038/sj.cdd.4402219; published online 21 September 2007

Nine inherited neurodegenerative disorders with expanded polyglutamine (polyQ) are caused by mutations in different genes, but they likely share the common pathology in which expanded polyQ gains toxic functions. ${ }^{1}$ The molecular mechanism of neuronal toxicity of polyQ remains enigmatic. Recent findings suggest that the intracellular aggregation of polyQ causes cellular stress responses that trigger neuronal cell death. ${ }^{1}$ It is hypothesized that polyQ aggregation suppresses neuronal transcriptional activity by sequestering histone acetyltransferases (HAT) from chromosomes and thus polyQ causes neuronal cell death. ${ }^{2-4}$

Bax is a proapoptotic member of $\mathrm{Bcl}-2$ family proteins that plays a key role in programmed cell death in neurons. ${ }^{5,6}$ Recently, mutant huntingtin with expanded polyQ was shown to activate p53 and increase the expression level of Bax. ${ }^{7}$ Based on these previous findings, we became interested in examining the role of Bax in polyQ-induced cell death. Recently, we developed a series of cytoprotective membrane-permeable pentapeptides that rescue cells from Baxmediated cell death. These peptides are named Bax-inhibiting peptides (BIPs) and were designed from the Bax binding domain of Ku70. ${ }^{8-10} \mathrm{Ku} 70$ is a multifunctional protein playing roles in DNA repair and cell survival. ${ }^{11} \mathrm{Ku} 70$ has been shown to inhibit Bax-mediated cell death by binding Bax in the cytosol. ${ }^{12-14}$ The present study demonstrates that BIP can rescue cells from poly $Q$ toxicity, and that polyQ promotes Bax-mediated cell death by inducing Ku70 acetylation that activates Bax.

\section{Results}

BIP suppresses Q79C-induced cell death. BIPs consisting of five amino acids (e.g. VPMLK and VPTLK) were used in this study. A mutated peptide (i.e. IPMIK) that does not bind Bax but retains cell permeability was also used in this study as a negative control (NC). For the investigation of polyQ toxicity, we used the C-terminal, truncated fragment of the Machado-Joseph disease 1 (MJD1) gene product, ataxin-3, which includes an expanded polyQ stretch (79 glutamine repeats, Q79C). ${ }^{15,16}$ As a negative control, ataxin3 C-terminus with 22 or 35 glutamine repeats (Q22C and Q35C, respectively) was used. ${ }^{15,16}$ BIP readily suppressed Q79C-induced cell death in a neuroblastoma cell line (Neuro2a) (Figure 1a and b) and in a human embryonic kidney cell line (HEK293T) (Figure 2a). Although these cell lines incorporated BIP very efficiently, ${ }^{9}$ the primary cultured rat cortical neurons showed very low uptake of BIP. To study whether BIP can suppress polyQ-induced cell death in primary cortical neurons, we utilized the protein transduction domain of the human immunodeficiency virus (HIV) trans-activator (TAT) ${ }^{17}$ to enhance cell permeability of BIP. PolyQ was expressed by an adenovirus vector. ${ }^{16} \mathrm{We}$ confirmed that TAT-BIP efficiently entered primary cortical neurons (Supplementary Figure 1), and it inhibited polyQinduced cell death in these cells (Figure 1c). To confirm the role of Bax in polyQ-induced cell death, we employed small interference RNA (siRNA) targeting Bax mRNA (Figure 1d).

\footnotetext{
${ }^{1}$ Department of Neurology and Neurological Science, Tokyo Medical and Dental University, Tokyo, Japan; ${ }^{2}$ Departments of Medicine and Pharmacology, Case Western Reserve University, Cleveland, OH, USA; ${ }^{3}$ Faculty of Life Sciences, Bar-llan University, Ramat-Gan, Israel and ${ }^{4}$ Paul F. Glenn Laboratories for the Molecular Biology of Aging, Department of Pathology, Harvard Medical School, Boston, MA, USA

${ }^{*}$ Corresponding authors: T Yokota, Department of Neurology and Neurological Science, Tokyo Medical and Dental University, Tokyo 113-8519, Japan.

Tel: + 8135803 5234; Fax: + 8135803 0169; E-mail: tak-yokota.nuro@tmd.ac.jp or S Matsuyama, Departments of Medicine and Pharmacology, Case Western Reserve University, Cleveland, OH 44106, USA. Tel: 216368 5832; Fax: 216368 8919; E-mail: shigemi.matsuyama@ @ase.edu

${ }^{5}$ These authors contributed equally to this work

Keywords: polyglutamine; Bax; Ku70; Acetylation; SIRT1

Abbreviations: polyQ, polyglutamine; MJD, Machado-Joseph disease; BIP, Bax-inhibiting peptide; LDH, lactate dehydrogenase; siRNA, small interference RNA; CBP, cyclic-AMP response element-binding protein; HDAC, histone deacetylase; TSA, trichostatin A

Received 22.12.06; revised 23.7.07; accepted 23.7.07; Edited by M Deshmukh; published online 21.9.07
} 
a
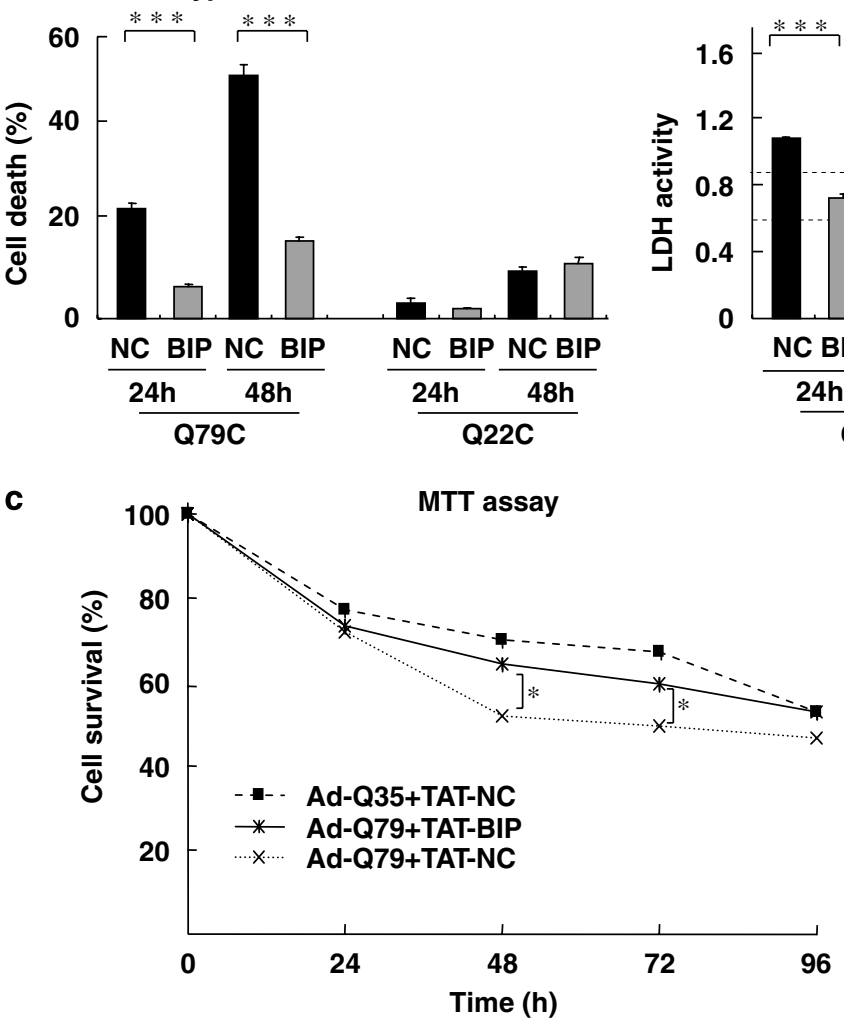

b



d e

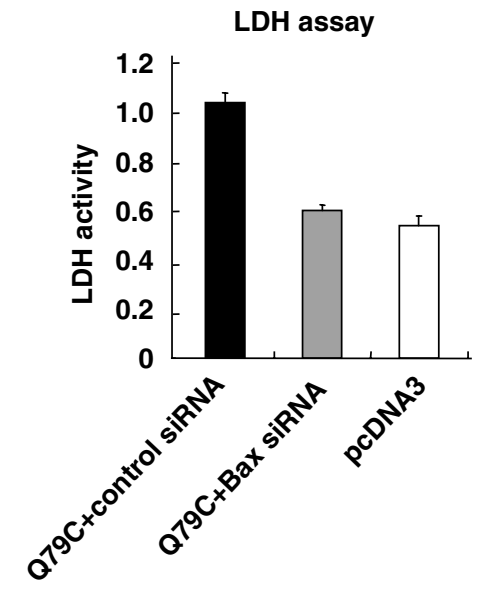

f

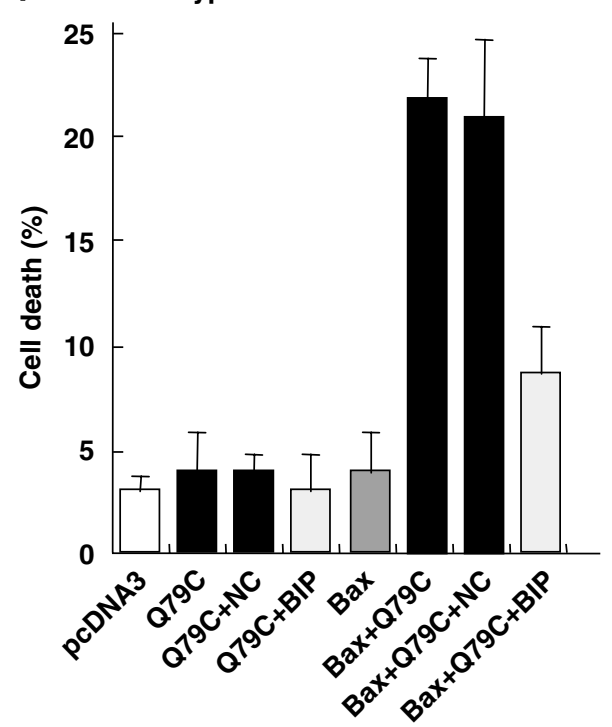

Figure 1 BIP suppresses Q79C-induced cell death. (a and $\mathbf{b})$ Neuro-2a cells in 24-well plates were transfected with pCMX HA-Q22C (0.5 $\mu \mathrm{g})$, pCMX HA-Q79C (0.5 $\mu \mathrm{g})$ or pcDNA3 $(0.5 \mu \mathrm{g})$ in the presence of $200 \mu \mathrm{M}$ VPTLK (BIP) or negative control peptide (IPMIK; NC). Cell death was analyzed by Trypan blue exclusion (a) or LDH release into the medium (b) at both 24 and $48 \mathrm{~h}$ after transfection; ${ }^{* \star} P<0.001$. (c) Primary cortical neurons in 24-well plates were infected with Ad-Q79C or Ad-Q35C at m.0.i. 100 in the presence of $80 \mu \mathrm{M}$ TAT-VPTLK (TAT-BIP) or negative control peptide (TAT-IPMIK; TAT-NC). Cell death was analyzed by MTT assay at $24,48,72$ and $96 \mathrm{~h}$ after treatment. The relative number of surviving cells was determined in triplicate by estimating the value of unstimulated or uninfected cells as $100 \%$; ${ }^{*} P<0.05$. (d and $\mathbf{e}$ ) The Bax siRNA suppresses Q79C toxicity. HEK293T cells in 24-well plates were transfected with pCMX HA-Q79C $(0.5 \mu \mathrm{g})$ and $100 \mathrm{nM}$ of control siRNA or Bax siRNA. The suppression of endogenous Bax expression by Bax siRNA was confirmed by Western blotting (d). The effect of Bax siRNA on Q79C-induced cell death is shown (e). (f) DU145 cells (Baxdeficient cells) in six-well plates were transfected with pcDNA3 $(1 \mu \mathrm{g})$, pCMX HA-Q79C $(1 \mu \mathrm{g})$ or pcDNA3-Bax $(0.25 \mu \mathrm{g})$, and were cultured in the presence or absence of $200 \mu \mathrm{M}$ VPMLK (BIP) or negative control peptide (IPMIK; NC). Cell death was analyzed by Trypan blue exclusion at $48 \mathrm{~h}$ after transfection 
a

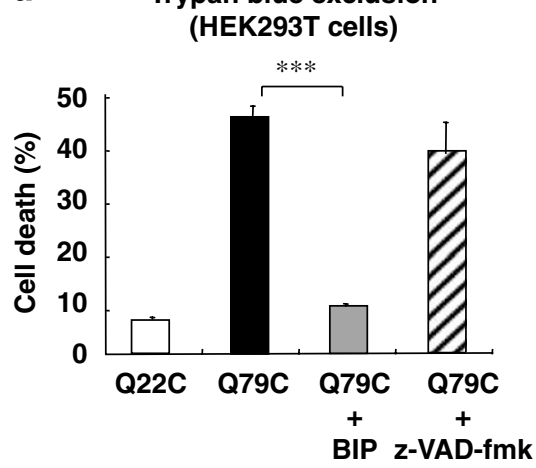

b

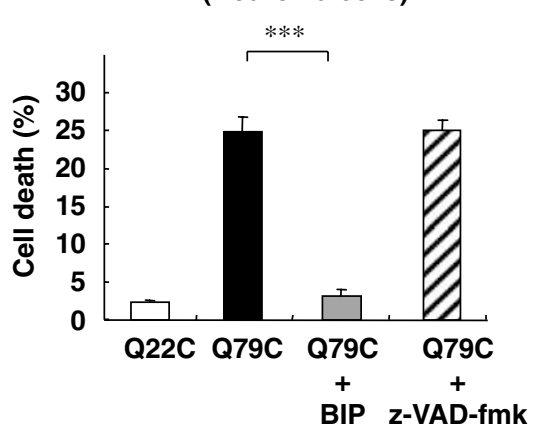

d
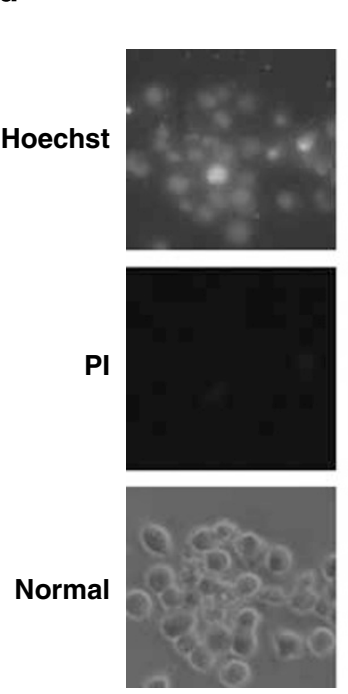

e
Q79C

$+15$
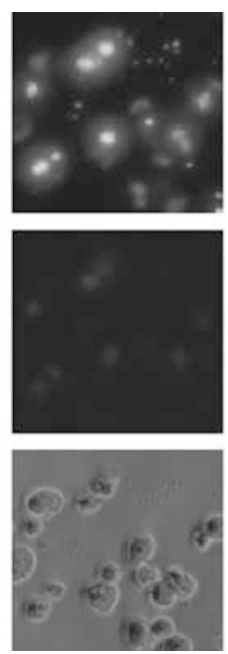
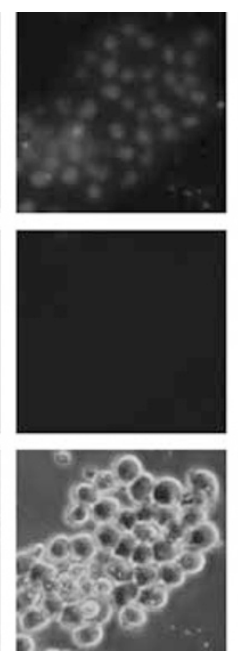

C

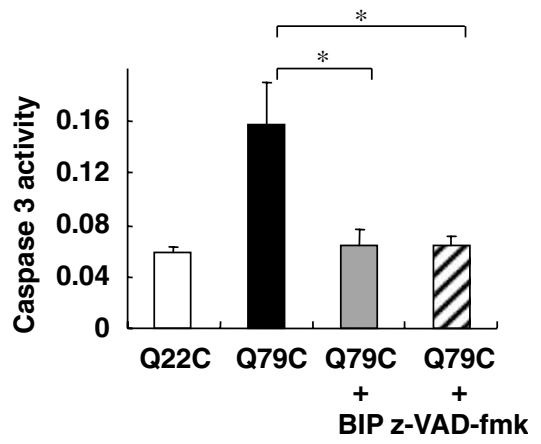

Q79C

+Z-VAD
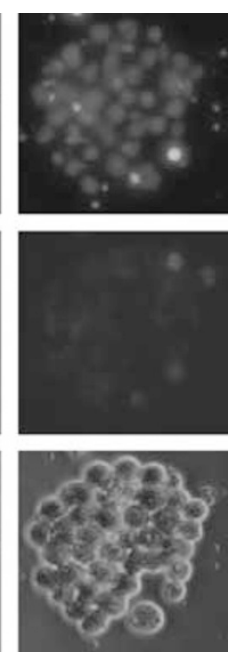

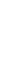


The siRNA significantly inhibited Q79C-induced cell death (Figure 1e). Furthermore, we examined the cytotoxicity of polyQ in a Bax-deficient cell line, DU145 (human prostate cancer cell line). ${ }^{18}$ Q79C did not show significant toxicity in DU145 cells, although Q79C induced cell death if Bax expression was restored (Figure 1f). These results suggest that Bax is a key mediator of Q79C-induced cell death.

BIP suppresses Q79C-induced nuclear fragmentation and cytoplasmic vacuolation. Next, we examined the effect of a pan-caspase inhibitor on Q79C-induced cell death, because Bax activates the caspases resulting in apoptosis. ${ }^{6}$ Unexpectedly, the pan-caspase inhibitor, z-VADfmk, did not show a significant cytoprotective effect against Q79C toxicity when cellular viability was examined by Trypan blue exclusion (Figure $2 \mathrm{a}$ and $\mathrm{b}$ ) and lactate dehydrogenase $(\mathrm{LDH})$ release from the cells into the medium (data not shown). To further determine the role of caspase in Q79Cinduced cell death, we examined the increase in caspase activity and the occurrence of nuclear fragmentation. We found that Q79C induced caspase activation (Figure 2c) and nuclear fragmentation (Figure $2 d$ and $e$ ), both of which could be attenuated by both inhibitors of Bax (BIP) and of caspases (z-VAD-fmk). Of note, the number of apoptotic cells detected by the presence of nuclear fragmentation (Figure $2 d$ and e) was less than the net number of dead cells detected by staining of Trypan blue (Figure $2 \mathrm{~b}$ ) and propidium iodide (PI) (Figure 2d and e), suggesting that Q79C activates both caspase-dependent and -independent cell death pathways.

PolyQ-induced cell death is associated with an increased number of enlarged vacuoles. ${ }^{19-21}$ We also found that Neuro- 2a cells with Q79C expression showed marked cytoplasmic vacuolation. BIP suppressed cytoplasmic vacuolation (Figure $3 a$ and $b$ ), whereas the caspase inhibitor did not. These results suggest that $\mathrm{Q79C}$-induced vacuolation is Baxdependent and caspase-independent. Collectively, BIP suppressed both caspase-dependent nuclear fragmentation and caspase-independent cytoplasmic vacuolation elicited by polyQ.

Q79C expression induces Ku70 acetylation that releases Bax from Ku70. Because BIP is designed from Ku70 which prevents Bax-mediated cell death, ${ }^{8-10}$ we examined whether Q79C had any influence on the binding between Ku70 and Bax. Q79C significantly decreased the interaction between Bax and Ku70 (Figure 4a and b). Furthermore, we found that Q79C induced significant acetylation of Ku70 (Figure 4c). To be noted, the acetylation of Ku70 is known to dissociate Bax and $\mathrm{Ku}{ }^{12}{ }^{12}$ Two lysine $(\mathrm{K})$ residues in Ku70, K539 and $\mathrm{K} 542$, are critical acetylation sites that influence Ku70-Bax binding. ${ }^{12}$ To test whether Ku70 acetylation plays a role for the activation of $\mathrm{Bax}$ by polyQ, we generated acetylationresistant mutants of Ku70 and acetylation-mimicking mutants of Ku70 by substituting $\mathrm{K} 539$ and $\mathrm{K} 542$ with arginine (R) or glutamine (Q), respectively. Acetylation-resistant Ku70 mutants (K539R and K542R) ${ }^{12}$ suppressed Q79C-induced cell death more efficiently than wild-type Ku70 (Figure 4d). In contrast, the acetylation-mimicking Ku70 mutants (K539Q and K542Q), ${ }^{12}$ could not suppress Q79C-induced cell death. The expression of these Ku70 mutants alone did not affect the cell viability. These results support the hypothesis that Q79C expression activates Bax, at least in part, through Ku70 acetylation. a
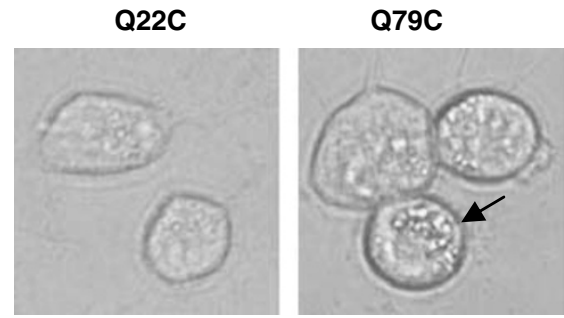

Q79C+BIP



$* * *$

b

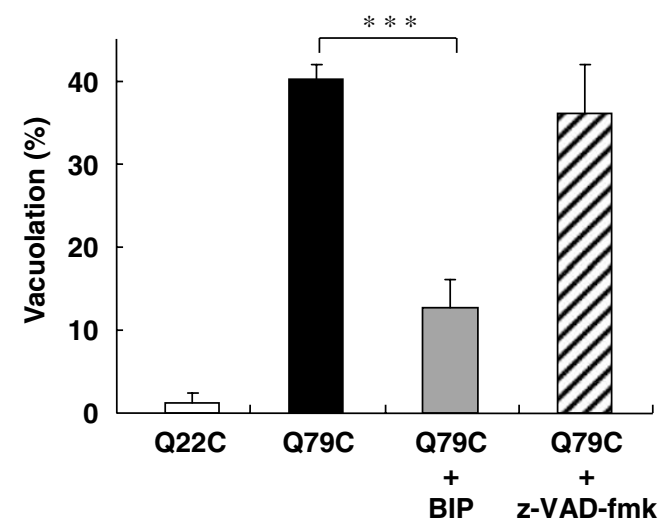

Q79C+z-VAD-fmk

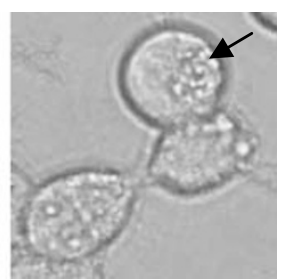

Figure 3 BIP suppresses Q79C-induced cytoplasmic vacuolation. Neuro-2a cells were transfected with pCMX HA-Q22C (0.5 $\mu \mathrm{g})$ or pCMX HA-Q79C $(0.5 \mu \mathrm{g})$ in the presence of $200 \mu \mathrm{M}$ VPTLK (BIP) or $100 \mu \mathrm{M}$ z-VAD-fmk. (a) At $48 \mathrm{~h}$ after transfection, the percent of cells with cytoplasmic vacuolation to all living cells were evaluated under optical microscopy $(\times 400) ;\left(\right.$ b) ${ }^{* \star *} P<0.001$ 
a

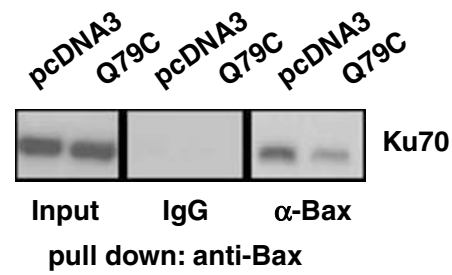

b

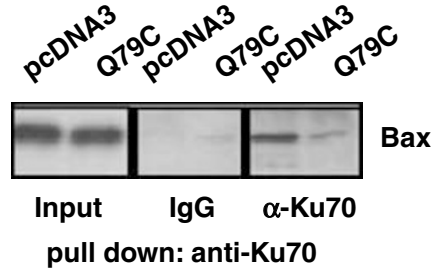

C

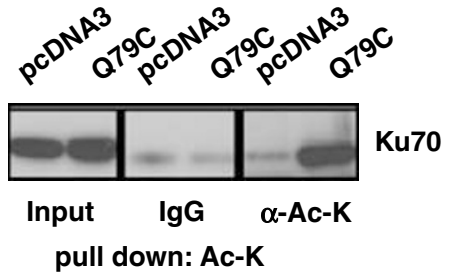

d

Trypan blue exclusion

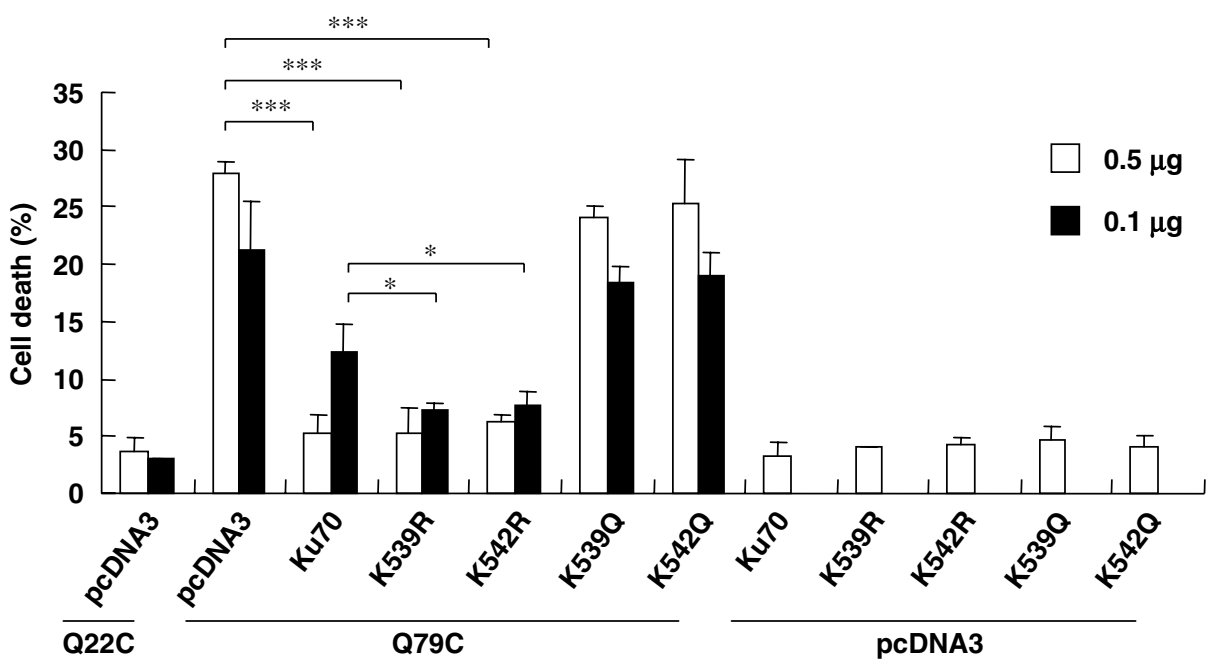

Figure 4 Q79C expression induces Ku70 acetylation that releases Bax from Ku70. (a and $\mathbf{b})$ HEK293T cells in 10-cm dishes were transfected with pcDNA3 (10 $\mu \mathrm{g}$ ) or pCMX HA-Q79C (10 $\mu \mathrm{g})$. At $48 \mathrm{~h}$ after transfection, cells were harvested and immunoprecipitation was performed using anti-Bax (a) and anti-Ku70 monoclonal antibodies (b). Normal mouse IgG (IgG) was used as a negative control. Western blotting was performed with anti-Ku70 (a) or anti-Bax polyclonal (b) antibody. (c) HEK293T cells in 10-cm dishes were transfected with pcDNA3 $(10 \mu \mathrm{g})$ or pCMX HA-Q79C $(10 \mu \mathrm{g})$. After $48 \mathrm{~h}$, cells were harvested and immunoprecipitation was performed using anti-pan-acetyllysine monoclonal antibody, and the acetylated Ku70 was detected by Western blotting with anti-Ku70 polyclonal antibody. (d) Neuro-2a cells in 24-well plates were cotransfected with pCMX HA-Q79C/Q22C $(0.5 \mu \mathrm{g})$ and pcDNA3 $(0.1 \mu \mathrm{g}$ or $0.5 \mu \mathrm{g})$, wild-type Ku70 $(0.1 \mu \mathrm{g}$ or $0.5 \mu \mathrm{g})$ or Ku70 mutants $(0.1 \mu \mathrm{g}$ or $0.5 \mu \mathrm{g})$ bearing $\mathrm{K} \rightarrow \mathrm{R}$ (acetylation-resistant mutation) or $\mathrm{K} \rightarrow \mathrm{Q}$ substitutions (mutation that mimics acetylation) at positions $\mathrm{K} 539$ and $\mathrm{K} 542$. Cell death was analyzed by Trypan blue exclusion (d) at $48 \mathrm{~h}$ after transfection; ${ }^{* \star} P<0.001$ or ${ }^{*} P<0.05$

Ku70 and BIP inhibit Bax conformational change induced by polyQ expression. In cells with apoptotic stimuli, Bax is known to change its conformation, and the conformational change can be detected using the 6A7 antiBax monoclonal antibody that recognizes the $\mathrm{N}$-terminus of Bax by immunoprecipitation. ${ }^{22,23}$ The $\mathrm{N}$-terminus exposure is an early step of Bax activation that occurs in the cytosol, and this conformational change is considered a prerequisite for membrane insertion of $\mathrm{Bax}$ at mitochondria and multimerization of Bax. ${ }^{22-24}$ We found that Ku70 wild type and acetylation-resistant Ku70 (Ku70(K539R)), but not acetylation-mimicking Ku70 mutant (Ku70(K539Q)), inhibited the conformational change that was induced by polyQ expression (Figure $5 \mathrm{a}$ and b). It was also confirmed that BIP treatment significantly blocked Bax conformational change (Figure 5c). These results further support our hypothesis that Ku70 as well as BIP protect cells from polyQ toxicity by inhibiting Bax-mediated cell death.

Q79C binds Ku70 and histone acetyl transferase. Next, we examined how Q79C expression results in the acetylation of Ku70. The cyclic-AMP response element-binding protein (CBP) has been shown to acetylate cytosolic Ku70 in response to apoptotic stimuli. ${ }^{12} \mathrm{Q79C}$ is known to bind
CBP in the nucleus. ${ }^{4}$ We found that this interaction occurs in the cytosol too. We performed co-immunoprecipitation of polyQ and CBP using the cytosolic fraction and found that CBP was co-immunoprecipitated with Q79C, but not with Q22C (Figure 6a). In addition, we found that Ku70 binds both $\mathrm{Q79C}$ and Q22C in the cytosolic fraction (Figure 6b). We further confirmed the interaction of Q79C and CBP in the cytosol fraction (Figure 6c). These results suggest that Q79C stimulates Ku70 acetylation by bridging Ku70 and CBP (Figure 6d).

SIRT1 deacetylase and resveratrol rescue Q79C-induced cell death. The significant role of Ku70 acetylation in Q79Cinduced cell death implies the possibility that the stimulation of deacetylases could reduce the polyQ toxicity. First, we examined the effect of the SIRT1 deacetylase, which has been demonstrated to deacetylate Ku70. ${ }^{12}$ Overexpression of SIRT1 suppressed Q79C-induced cell death in Neuro-2a cells (Figure $7 a$ and b). Small polyphenolic molecules such as resveratrol have been found to increase the affinity of SIRT1 and its target proteins. ${ }^{25}$ We found that resveratrol markedly suppressed the cell death induced by Q79C in the HEK293T cells and primary cortical neurons (Figure 7c-e). We confirmed that SIRT1expression and resveratrol 
a

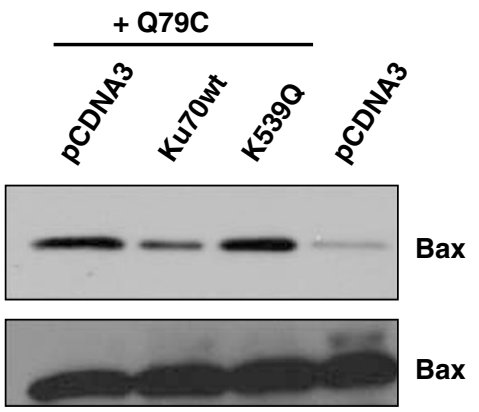

b

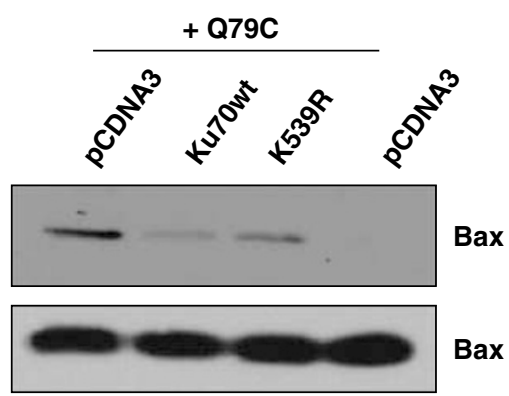

c

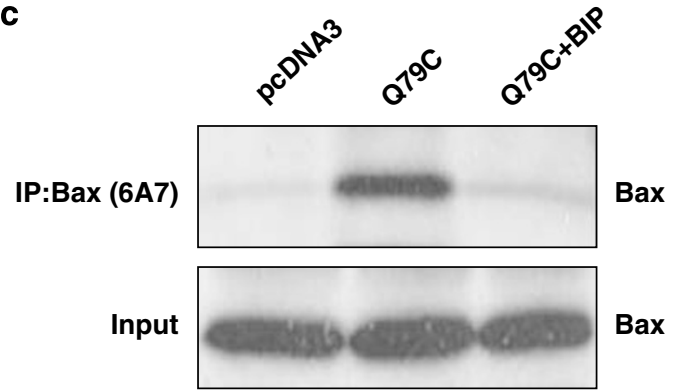

Figure 5 Ku70 and BIP inhibit Bax conformational change induced by polyQ expression. ( $\mathbf{a}$ and $\mathbf{b}$ ) Ku70 inhibits conformational change of Bax induced by Q79C. Neuro2a cells in 10-cm dishes were transfected with pcDNA3 $(5 \mu \mathrm{g})$ or pCMX HAQ79C $(5 \mu \mathrm{g})$ together with pCMV-2B-Ku70 $(5 \mu \mathrm{g}), \mathrm{K} 539 \mathrm{Q}$ (acetylation-mimicking mutant) $(5 \mu \mathrm{g})$ or $\mathrm{K} 539 \mathrm{R}$ (acetylation-resistant mutant). After $48 \mathrm{~h}$, cells were harvested and immunoprecipitation was performed using $6 \mathrm{~A} 7$ anti-Bax monoclonal antibody. (c) HEK293T cells in 10-cm dishes were transfected with pcDNA3 $(10 \mu \mathrm{g})$ or pCMX HA-Q79C $(10 \mu \mathrm{g})$ in the presence or absence of $200 \mu \mathrm{M}$ VPMLK (BIP). After $48 \mathrm{~h}$, cells were harvested and immunoprecipitation was performed using $6 \mathrm{~A} 7$ anti-Bax monoclonal antibody

treatment reduced the acetylation levels of Ku70 that was increased by Q79C expression (Figure 7f).

\section{Discussion}

We demonstrated that the inhibition of Bax by Ku70 and BIP markedly protected cells from polyQ toxicity. These results indicate that Bax plays a key role in polyQ toxicity. Our data also suggest that polyQ expression activates two different pathways of cell death. One is caspase-dependent cell death associated with nuclear fragmentation, and the other is caspase-independent cell death associated with cytoplasmic vacuolation, both of which were dramatically decreased by BIP. Cytoplasmic vacuolation has been observed in the neurons of patients with polyQ diseases. ${ }^{19-21}$ Importantly, Bax is known to induce both caspase-independent and dependent cell death with cytoplasmic vacuolation when caspase activity is inhibited or absent. ${ }^{26-28}$ These previous reports support our hypothesis that Bax is a key mediator of Q79C-induced cell death associated with cytoplasmic vacuolation. Recently, an elevated expression of Bax was reported in the brain of polyQ-transgenic mouse. ${ }^{29,30} \mathrm{We}$ also observed that the number of pontine nucleus and microglia stained by anti-Bax 6A7-Ab in the brain section of MJD patient was significantly higher than those of normal controls (Supplementary Figure 3). Although this result is consistent with our findings in cell culture system, there are potential limitations of such experiments using human tissue, as the conditions and timing of specimen collection cannot be strictly controlled. Further extensive investigation is needed to determine the role of Bax in MJD pathogenesis in patient brain.

The significant ability of BIP to suppress Q79C-induced cell death suggests the possibility that Q79C expression causes dissociation of Ku70 from Bax. Previously, we reported that apoptotic stimuli decreased cytosolic levels of Ku70, and that this change may be one of the mechanisms for Ku70 dissociation from Bax. ${ }^{31}$ However, in the case of Q79C expression, the decrease of Ku70 levels was not clear (Figure $4 \mathrm{a}$ and c, Ku70 input). The acetylation of Ku70 is known to be another mechanism releasing Bax from Ku70. ${ }^{12}$ As shown in Figure 4, Q79C induced a significant acetylation of Ku70. We also confirmed that Ku70 mutants mimicking acetylation did not suppress Q79C-induced cell death, whereas acetylationresistant Ku70 mutants rescued cells from Q79C toxicity more efficiently than Ku70 wild type. These results suggest that Ku70 acetylation is one of the major causes of Bax activation in Q79C-expressing cells.

SIRT1, one of the mammalian silent information regulator 2 (Sir2) homologues, was identified as a cell survival factor that protects cells from DNA damage. ${ }^{32}$ SIRT1 was shown to have the activity to deacetylate several transcription factors, and through this activity, SIRT1 regulates a wide array of cellular processes for cell defense and survival under various stress conditions (reviewed by Baur and Sinclair ${ }^{25}$ ). Recently, resveratrol, an activator of the Sir2 histone deacetylase (HDAC), ${ }^{25}$ has been reported to rescue polyQ-induced neuronal dysfunction in Caenorhabditis elegans. ${ }^{33}$ Similarly, in the present study, SIRT1 deacetylase and resveratrol both effectively rescued cultured cells from polyQ toxicity. We confirmed that Ku70 was acetylated by Q79C and that Ku70 was deacetylated by resveratrol and SIRT1. These observations support our hypothesis that Ku70 acetylation plays an important role in Q79C-induced cell death.

It has been hypothesized that polyQ toxicity is caused by decreased histone acetylation, as poly $Q$ sequesters histone acetyl transferase (HAT) (e.g. CBP) from chromosomes. ${ }^{2,3}$ The subsequent suppression of histone acetylation decreases cellular transcriptional activities, and these changes are implicated to cause polyQ toxicity. Based on this hypothesis, the maintenance of histone acetylation by HDAC inhibitors, such as trichostatin A (TSA), has been examined for the reduction of polyQ toxicity. ${ }^{3,34,35}$ However, an HDAC inhibitor was recently shown to induce apoptosis in neuroblastoma cells by increasing Ku70 acetylation and promoting Bax-mediated cell death. ${ }^{14}$ Therefore, it is plausible that HDAC inhibitors have a 'double-edge' activity in the context of 

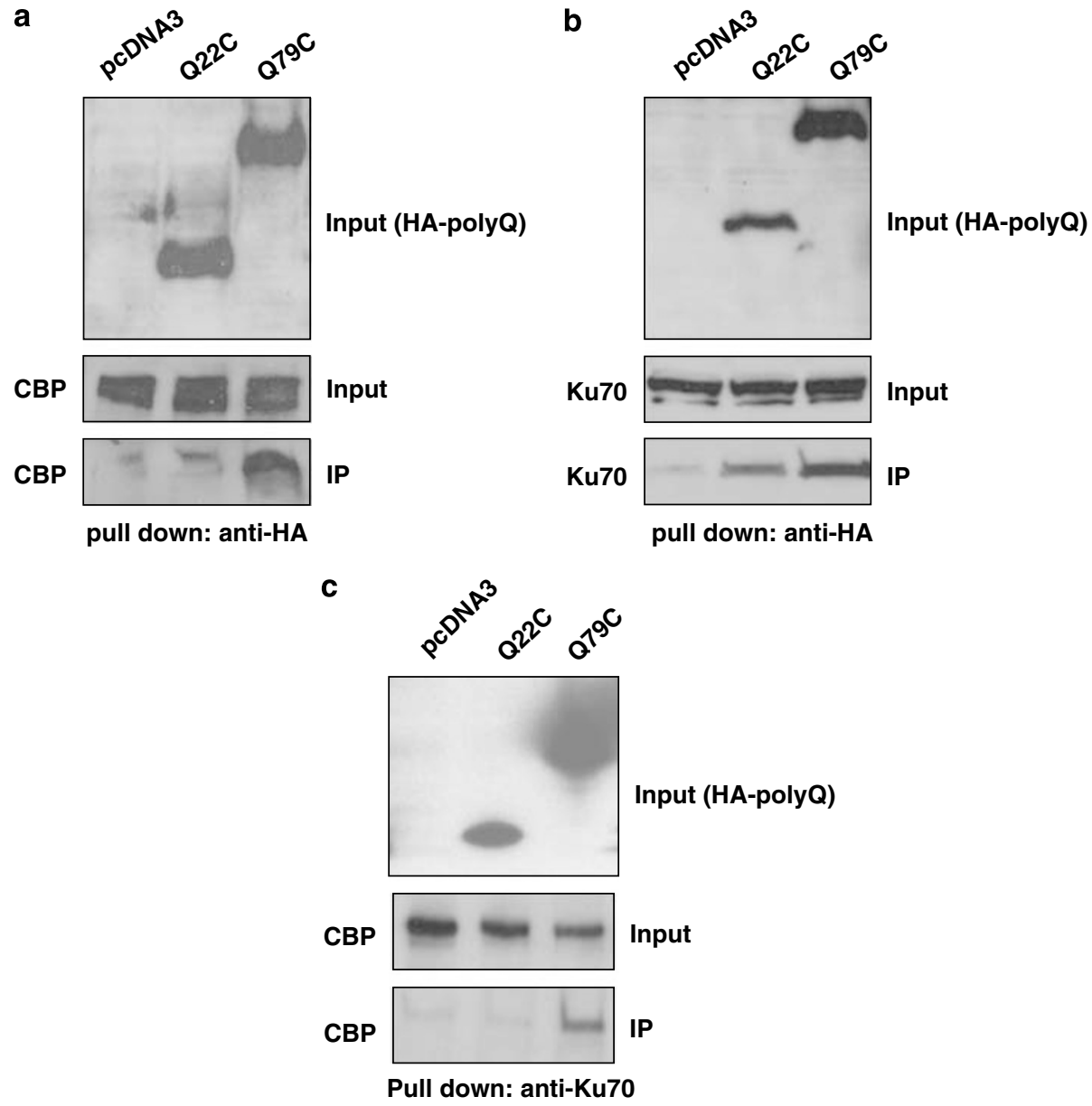

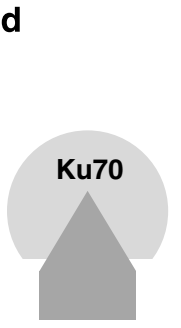

Inactive Bax

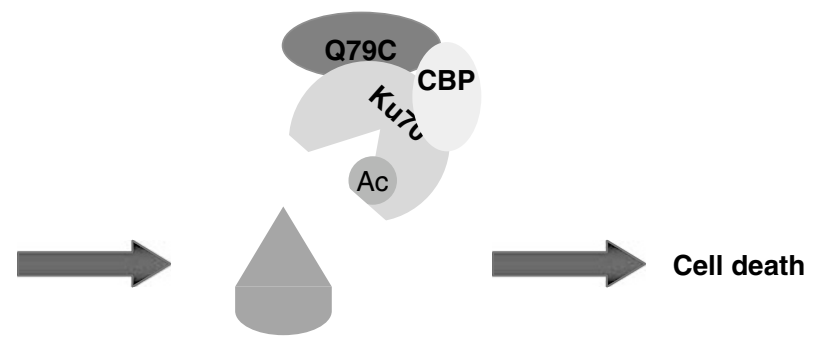

Figure 6 Q79C binds Ku70 and CBP. (a-c) HEK293T cells were transfected as described in Figure 4a and b, and the cytosolic fraction was used for immunoprecipitation. Immunoprecipitation was performed using anti-HA (a and $\mathbf{b}$ ) or anti-Ku70 monoclonal antibody (c). Western blotting analyses of HA-tagged polyQ (Q22C and Q79C), CBP and Ku70 are shown. (d) Schematic representation of Bax activation by Ku70 acetylation during Q79C-induced cell death

polyQ toxicity; they attenuate polyQ toxicity by maintaining histone acetylation in the nucleus, but promote Bax-mediated cell death by acetylating Ku70 in the cytosol. In cultured cells, TSA can attenuate $Q 79 C$-induced cell death only at the lower doses (3-10 nM), whereas it enhances cell death at the higher doses (more than $20 \mathrm{nM}$ ) (Supplementary Figure 2). Actually, the therapeutic effect of an HDAC inhibitor was observed only within a narrow range of lower doses, and the effect changed to be toxic at higher doses in poly $Q$ transgenic mice. ${ }^{35}$ These results suggest that the use of HDAC inhibitors in polyQ diseases requires careful consideration to avoid causing a lethal degree of Ku70 acetylation. The present study focused on the toxicity of expanded polyQ derived from the causative gene (mutated ataxin3) of MJD. Thus, further study is needed to examine whether our observation can be generally confirmed in other types of toxic polyQ such as that of Huntington's disease and spinocerebellar ataxia type 1 (SCA1).

In conclusion, we propose that Bax is a key mediator of Q79C-induced cell death and that Bax activation is mediated through acetylation of Ku70, which dissociates Bax from Ku70. Our hypothesis is based on the observation in cell culture studies, and further extensive studies using in vivo models are clearly needed. The present study suggests that 
a

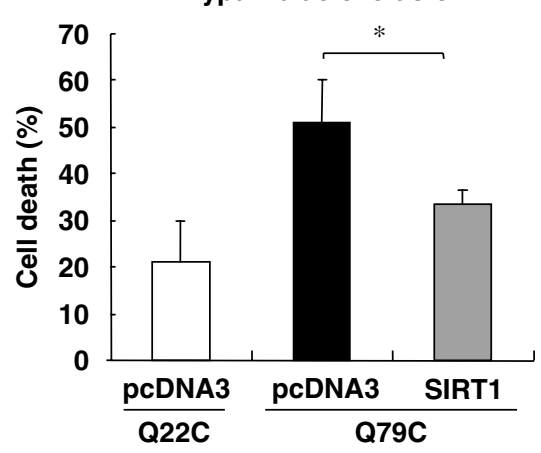

C

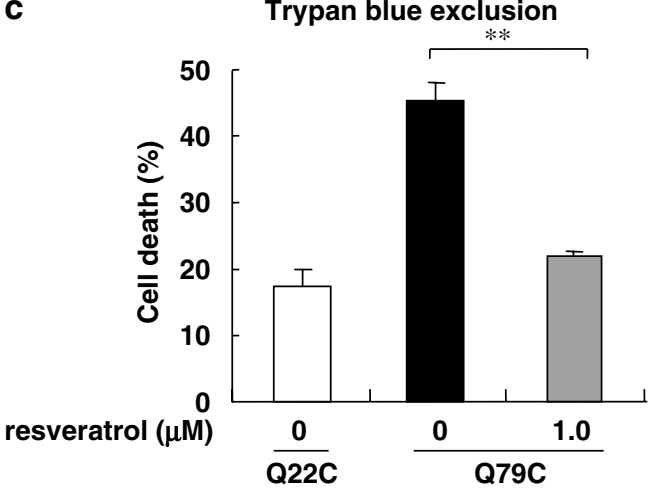

b

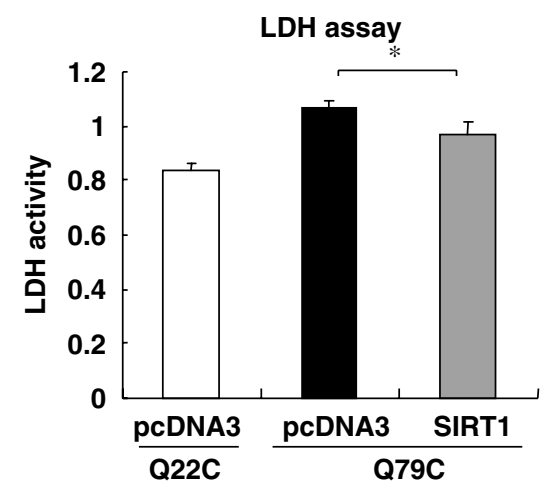

d

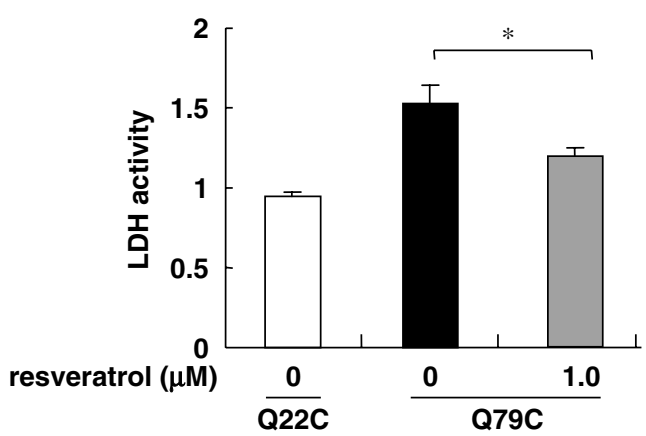

e MTT assay f
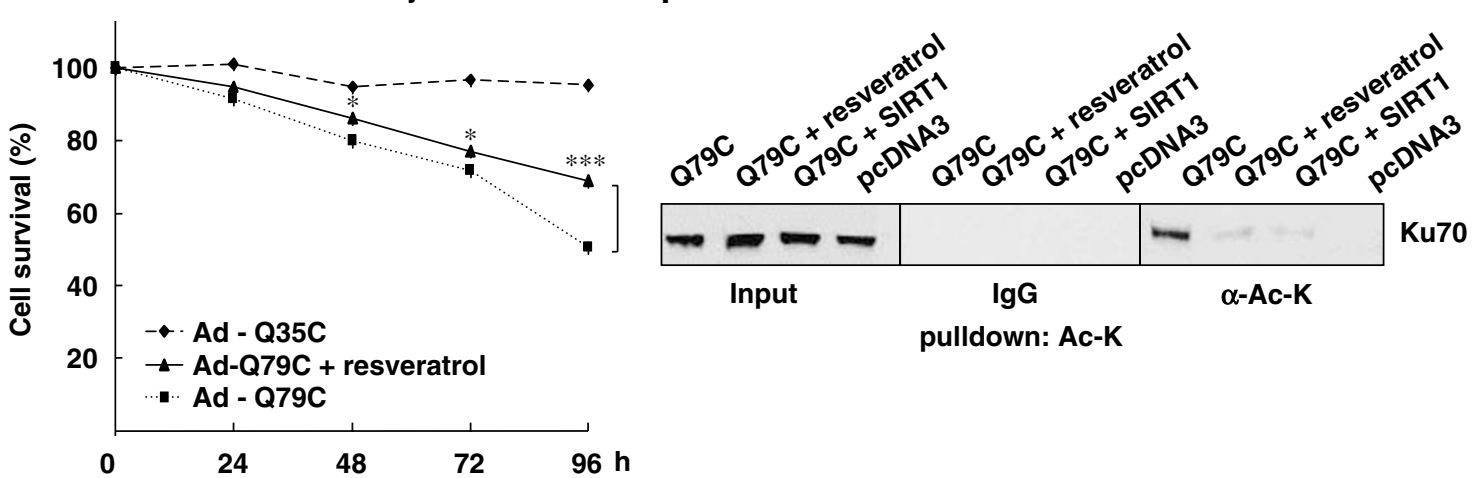

pulldown: Ac-K $6 \mathrm{~h}$

Figure 7 Effects of SIRT1 and resveratrol on Q79C-induced cell death. Neuro-2a cells in 24-well plates were co-transfected with pCMX HA-Q79C or -Q22C (0.5 $\mu \mathrm{g})$ and pcDNA3 $(0.5 \mu \mathrm{g})$, or pcDNA3-SIRT1 $(0.5 \mu \mathrm{g})$. Cell death was analyzed by Trypan blue exclusion (a) or LDH release into the medium (b) at $48 \mathrm{~h}$ after transfection; ${ }^{*} P<0.05$. HEK293T cells in 24-well plates were transfected with pCMX HA-Q79C $(0.5 \mu \mathrm{g})$ or pCMX HA-Q22C $(0.5 \mu \mathrm{g})$ in the presence of resveratrol $(1 \mu \mathrm{M})$. Cell death was assessed by Trypan blue exclusion (c) or LDH release into the medium (d) at $72 \mathrm{~h}$ after transfection; ${ }^{\star *} P<0.01$ or ${ }^{\star} P<0.05$. (e) Primary cortical neurons in 24-well plates were infected with Ad-Q79C or Ad-Q35C at m.0.i. 100 in the presence of resveratrol $(1 \mu \mathrm{M})$. Cell death was analyzed by MTT assay at $24,48,72$ and $96 \mathrm{~h}$ after treatment. The relative number of surviving cells was determined in triplicate by estimating the value of unstimulated or uninfected cells as $100 \%$; ${ }^{* * *} P<0.001$ or ${ }^{*} P<0.05$. (f) HEK293T cells in 10 -cm dishes were transfected with pCMX HA-Q79C $(5 \mu \mathrm{g})$ and pcDNA3-SIRT1 $(5 \mu \mathrm{g})$, or with pCMX HA-Q79C $(5 \mu \mathrm{g})$ in the presence of resveratrol $(1 \mu \mathrm{M})$. After $48 \mathrm{~h}$, cells were harvested and immunoprecipitation was performed using anti-pan-acetyl-lysine monoclonal antibody. The acetylated Ku70 was detected by Western blotting with anti-Ku70 polyclonal antibody

the inhibition of Bax by BIPs or Ku70 may provide a new strategy to develop therapeutics for MJD.

\section{Materials and Methods}

Plasmid constructs and recombinant adenoviruses. The expression plasmids of ataxin-3 were kindly given Dr. Akira Kakizuka. The MJD1 CDNA in the plasmid was a truncated fragment including either 22 (normal, pCMX HA-Q22C) or 79 (expanded, pCMX HA-Q79C) repeats of CAG, and was hemagglutinin (HA)-fused on the N-terminus. The plasmids, pcDNA3-Bax and
pCMV 2B-Flag-Ku70 have been described previously. ${ }^{12}$ pCMV 2B-Flag-Ku70 K539R/K542R/K539Q/K542Q were generated by QuickChange Site-Directed Mutagenesis Kit from Stratagene. SIRT1 expression plasmid was generated by subcloning the coding sequence of SIRT1 cDNA (kindly provided by Dr. Shinichirou Imai) into the pcDNA3 vector (Invitrogen). Recombinant adenoviruses encoding Flag-Q79C and Flag-Q35C were constructed as described previously. ${ }^{36}$

Cell culture and transfection. HEK293T, Neuro-2a and DU145 cells were cultured in DMEM containing 10\% fetal bovine serum. Transfection of plasmids was 
performed with Lipofectamine Plus reagent (Invitrogen) in accordance with the manufacturer's instructions. For cell death analysis with HEK293T and Neuro-2a cells, transfection efficiency was monitored with co-transfected $50 \mathrm{ng}$ of pEGFP-C2 (Clontech), and confirmed that the efficiency was more than $75 \%$ before analysis.

Rat primary cortical neurons. Cortices were dissected from E-18 SpragueDawley rats' brains. Rat cortical neurons were plated into poly-D-lysine-coated 24well plates. Mixed cultures were maintained in neurobasal medium. After $72 \mathrm{~h}$ of culture, $10 \mathrm{mM}$ of cytosine arabinoside (Ara-C) was added to stop the proliferation of glial cells. After $72 \mathrm{~h}$ of Ara-C-treated, medium was replaced with fresh neurobasal medium.

Cell death assays. Cell death was assessed by Trypan blue exclusion, $\mathrm{PI}$ exclusion, LDH relase, Hoechst dye nuclear staining, MTT assay and caspase activity measurement.

For Trypan blue exclusion test, cells were collected and centrifuged for $10 \mathrm{~min}$ at 1000 r.p.m. The cell pellet was resuspended in $50 \mu \mathrm{l}$ of DMEM, to which $50 \mu \mathrm{l}$ of Trypan blue $(0.4 \%)$ was added. Dead cells were counted by three independent hemocytometer counts.

LDH release from the cells into the medium was analyzed by the Cytotox 96 nonradioactive cytotoxicity assay (Promega). Cell viability of primary cortical neurons was determined by MTT assay (Chemicon) and LDH release into the medium. Nuclear condensation and membrane integrity loss were monitored by observing cells under a fluorescence microscope after application of $1 \mu \mathrm{g} / \mathrm{ml}$ Hoechst dye 33258 and $4 \mu \mathrm{g} / \mathrm{ml} \mathrm{PI}$. Caspase 3 activities of cells were measured with Caspase 3 Assay Kit (Sigma) in accordance with the manufacturer's instructions. For each experiment, data were obtained from three wells.

Statistical analyses for cell death were performed using the student's $t$-test and single-factor ANOVA, followed by Fisher's protected least-significant difference post hoc test. The results were confirmed in more than three independent experiments of all cell death analysis and Western blottings.

siRNA preparation. Sense and antisense strands of siRNA oligonucleotides were synthesized, and were then annealed at $95^{\circ} \mathrm{C}$ for $1 \mathrm{~min}$. The sense sequence of siRNA-Bax is $5^{\prime}$-CCAAGAAGCUGAGCGAGUGdTdT- $3^{\prime}$ and the sequence of control siRNA is $5^{\prime}$-GGUCUCGUAGACCGUGCACdTdT- $3^{\prime}$.

Immunoprecipitation. For detecting the active form of Bax (Figure 5a-c), transfected HEK293T cells in 10-cm dishes were lysed in $200 \mu$ l Chaps buffer (150 mM NaCl, $10 \mathrm{mM} \mathrm{HEPES}$ at pH 7.4 and 1.0\% Chaps) containing the protease inhibitors (1:100 dilution of protease inhibitor Cocktail; Sigma), according to the previously reported methods. ${ }^{22}$ After pre-clearing $200 \mu \mathrm{l}$ of the sample with $20 \mu \mathrm{l}$ protein A-sepharose (CL-4B, 17-0780-01; Amersham Biosciences) at $4^{\circ} \mathrm{C}$ for $1 \mathrm{~h}$, immunoprecipitation was performed by incubating $200 \mu$ of the lysates with $2 \mu \mathrm{g}$ of anti-Bax monoclonal antibody (clone 6A7, BD-Pharmingen) at $4^{\circ} \mathrm{C}$ for $2 \mathrm{~h}$. Immunocomplexes in $200 \mu$ l of the lysates were precipitated with $20 \mu$ l protein Asepharose. After extensive washing with buffer, beads were boiled in $40 \mu \mathrm{l} \mathrm{Laemmli}$ buffer, and $20 \mu$ of the eluted proteins were analyzed by Western blotting. Western blotting analysis of pre-immunoprecipitation (input) and immunoprecipitated samples (IP) were performed with an anti-Bax polyclonal antibody (N-20, sc-493; Santa Cruz).

For detecting Bax-Ku70 interactions (Figure 4a and b), transfected HEK293T cells in 10-cm dishes were lysed in $200 \mu$ l Chaps buffer containing the protease inhibitors. After pre-clearing $200 \mu \mathrm{l}$ of the sample with $20 \mu \mathrm{l}$ protein G-sepharose (4 Fast Flow, 17-0618-01; Amersham Biosciences) at $4^{\circ} \mathrm{C}$ for $1 \mathrm{~h}$, immunoprecipitation was performed by incubating $200 \mu \mathrm{l}$ of the lysates with $2 \mu \mathrm{g}$ of monoclonal anti-Bax antibody (B9, Santa Cruz) or $2 \mu \mathrm{g}$ of monoclonal anti-Ku70 antibody (A9, Santa Cruz) at $4{ }^{\circ} \mathrm{C}$ for $2 \mathrm{~h}$. Immunocomplexes in $200 \mu \mathrm{l}$ of the lysates were precipitated with $20 \mu \mathrm{L}$ protein $\mathrm{G}$-sepharose. After extensive washing with buffer, beads were boiled in $40 \mu \mathrm{l}$ Laemmli buffer, and $20 \mu \mathrm{l}$ of the eluted proteins were analyzed by Western blotting. Mouse IgG was used as negative control. Western blotting analysis of pre-immunoprecipitation (input) and immunoprecipitated samples ( $\alpha$-Bax or $\alpha$-Ku70) were performed with an anti-Ku70 polyclonal antibody (H-308, sc-9033; Santa Cruz) or an anti-Bax polyclonal antibody (N-20, sc-493; Santa Cruz).

For detecting the acetylated form of Ku70 (Figures $4 \mathrm{c}$ and $7 \mathrm{f}$ ), transfected HEK293T cells in 10-cm dishes were lysed in $200 \mu \mathrm{l} \%$ triton in phosphate-buffered saline containing the protease inhibitors and $5 \mu \mathrm{M} \mathrm{TSA}$ (Sigma). ${ }^{12}$ After pre-clearing $200 \mu \mathrm{l}$ of the sample with $20 \mu \mathrm{l}$ protein G-sepharose at $4^{\circ} \mathrm{C}$ for $1 \mathrm{~h}$, immunoprecipitation was performed by incubating $200 \mu$ l of the lysates with $4 \mu \mathrm{g}$ of anti-pan-acetyl-lysine monoclonal antibody (9681S; Cell Signaling) at $4^{\circ} \mathrm{C}$ for $2 \mathrm{~h}$. Immunocomplexes in $200 \mu \mathrm{l}$ of the lysates were precipitated with $20 \mu \mathrm{l}$ protein G-sepharose. After extensive washing with buffer, beads were boiled in $40 \mu \mathrm{l}$ Laemmli buffer, and $20 \mu \mathrm{l}$ of the eluted proteins were analyzed by Western blotting. Mouse IgG was used as negative control. Western blotting analysis of preimmunoprecipitation (input) and immunoprecipitated samples $(\alpha-A c-K)$ were performed with an anti-Ku70 polyclonal antibody (H-308, sc-9033; Santa Cruz).

For detecting the interactions of HA-polyQ (Q79C) and CBP or Ku70, Ku70 and CBP (Figure 6a-C), transfected HEK293T cells in 10-cm dishes were homogenized with $350 \mu$ l of ice-cold homogenization buffer $(250 \mathrm{mM}$ sucrose, $20 \mathrm{mM}$ HEPES at $\mathrm{pH}$ 8.0, $10 \mathrm{mM} \mathrm{KCl}, 1.5 \mathrm{mM} \mathrm{MgCl}, 1 \mathrm{mM}$ EDTA, $1 \mathrm{mM}$ EGTA, pH 7.5 and $0.1 \mathrm{mM}$ PMSF) containing the protease inhibitors. The cytosolic fraction was prepared by collecting the supernatant of the centrifuged homogenate samples at 14000 r.p.m. for $30 \mathrm{~min}$ at $4^{\circ} \mathrm{C}$. Immunoprecipitation was performed by incubating $300 \mu$ lof the lysates with $40 \mu \mathrm{l}$ of anti-HA antibody-conjugated beads (HA-7, A2095; Sigma) or with $2 \mu \mathrm{g}$ anti-Ku70 monoclonal antibody (A-9, sc-5309; Santa Cruz) at $4{ }^{\circ} \mathrm{C}$ for $2 \mathrm{~h}$. Immunocomplexes of anti-Ku70 monoclonal antibody in $200 \mu$ of the lysates were precipitated with $20 \mu \mathrm{l}$ protein G-sepharose beads (4 Fast Flow, 17-0618-01; Amersham Biosciences). After extensive washing with buffer, beads were boiled in $40 \mu \mathrm{l}$ Laemmli buffer, and $20 \mu \mathrm{l}$ of the eluted proteins were analyzed by Western blotting. Western blotting analysis of pre-immunoprecipitation (input) and immunoprecipitated samples (IP) were performed with an anti-HA polyclonal antibody (HA-7, H9658; Sigma), anti-CBP polyclonal antibody (C-20, sc-583; Santa Cruz) or anti-Ku70 polyclonal antibody (H-308, sc-9033; Santa Cruz).

Acknowledgements. We thank Dr. Akira Kakizuka for providing ataxin-3expressing plasmid, Dr. Hideki Nishitoh for recombinant adenoviruses encoding Q79C and Q35C, Dr. Shinichirou Imai for providing mouse SIRT1 cDNA and Dr. Hideki Mochizuki for providing mouse tissue sample treated with MPTP as positive control of activated Bax. We also thank Ms. Keiko Kaneko, Ms. Kanae Yonetsu and Ms. Iku Sudo for their technical help. This work was supported in part by a grant from the 21st Century COE Program on Brain Integration and its Disorders to Tokyo Medical and Dental University (to YL and HM), Japan Foundation for Neuroscience and Mental Health (to YL, TY and HM), National Institute of Health (USA) (P20CA10373 to SM) and American Heart Association (to VG (predoctoral fellowship), JG (predoctoral fellowship) and SM (Grant-in-Aid)).

1. Ross CA. Polyglutamine pathogenesis: emergence of unifying mechanisms for Huntington's disease and related disorders. Neuron 2002; 35: 819-822.

2. Shimohata T, Nakajima Tm, Yamada M, Uchida C, Onodera O, Naruse S. Expanded polyglutamine stretches interact with TAFII130, interfering with CREB-dependent transcription. Nat Genet 2000; 26: 29-36.

3. Steffan JS, Bodai L, Pallos J, Poelman M, McCampbell A, Apostol BL et al. Histone deacetylase inhibitors arrest polyglutamine-dependent neurodegeneration in Drosophila. Nature 2001; 413: 739-743.

4. Li F, Macfarlan T, Pittman RN, Chakravarti D. Ataxin-3 is a histone-binding protein with two independent transcriptional corepressor activities. J Biol Chem 2002; 277: 45004-45012.

5. Deckwerth TL, Elliott JL, Knudson CM, Johnson Jr EM, Snider WD, Korsmeyer SJ. BAX is required for neuronal death after trophic factor deprivation and during development. Neuron 1996; 17: 401-411.

6. Vaux DL, Korsmeyer SJ. Cell death in development. Cell 1999; 96: 245-254.

7. Bae Bl, Xu H, Igarashi S, Fujimuro M, Agrawal N, Taya $Y$ et al. p53 mediates cellular dysfunction and behavioral abnormalities in Huntington's disease. Neuron 2005; 47: 29-41.

8. Yoshida T, Tomioka I, Nagahara T, Holyst T, Sawada M, Hayes P et al. Bax-inhibiting peptide derived from mouse and rat Ku70. Biochem Biophys Res Commun 2004; 321 : 961-966.

9. Gomez JA, Gama V, Matsuyama S. Cell-permeable penta-peptides derived from Baxinhibiting peptide. Handbook of Cell Penetrating Peptides, 2nd edn., CRC Press: Ulo Langel, 2006, pp 469-481.

10. Gomez J, Gama V, Yoshida T, Sun W, Hayes P, Leskov K et al. Bax Inhibiting Peptides (BIPs) derived from Ku70 and Cell Penetrating Penta-Peptides (CPP5s). Biochem Soc Trans 2007; 35: 797-801.

11. Downs JA, Jackson SP. A means to a DNA end: the many roles of Ku. Nat Rev Mol Cell Biol 2004; 5: 367-378.

12. Cohen HY, Lavu S, Bitterman KJ, Hekking B, Imahiyerobo TA, Miller $C$ et al. Acetylation of the $\mathrm{C}$ terminus of Ku70 by CBP and PCAF controls Bax-mediated apoptosis. Mol Cell 2004; 13: 627-638.

13. Cohen HY, Miller C, Bitterman KJ, Wall NR, Hekking B, Kessler B et al. Calorie restriction promotes mammalian cell survival by inducing the SIRT1 deacetylase. Science 2004; 305: 390-392. 
14. Subramanian C, Opipari Jr AW, Bian X, Castle VP, Kwok RP. Ku70 acetylation mediates neuroblastoma cell death induced by histone deacetylase inhibitors. Proc Natl Acad Sci USA 2005; 102: 4842-4847.

15. Ikeda H, Yamaguchi M, Sugai S, Aze Y, Narumiya S, Kakizuka A. Expanded polyglutamine in the Machado-Joseph disease protein induces cell death in vitro and in vivo. Nat Genet 1996; 13: 196-202.

16. Nishitoh H, Matsuzawa A, Tobiume K, Saegusa K, Takeda K, Inoue K et al. ASK1 is essential for endoplasmic reticulum stress-induced neuronal cell death triggered by expanded polyglutamine repeats. Genes Dev 2002; 16: 1345-1355.

17. Xia $H$, Mao Q, Davidson BL. The HIV Tat protein transduction domain improves the biodistribution of beta-glucuronidase expressed from recombinant viral vectors. Nat Biotechnol 2001; 19: 640-644.

18. Rampino N, Yamamoto H, lonov Y, Li Y, Sawai H, Reed JC et al. Somatic frameshift mutations in the BAX gene in colon cancers of the microsatellite mutator phenotype. Science 1997; 275: 967-969.

19. Clark HB, Burright EN, Yunis WS, Larson S, Wilcox C, Hartman B et al. Purkinje cell expression of a mutant allele of SCA1 in transgenic mice leads to disparate effects on motor behaviors, followed by a progressive cerebellar dysfunction and histological alterations. J Neurosci 1997; 17: 7385-7395.

20. Sapp E, Schwarz C, Chase K, Bhide PG, Young AB, Penney J et al. Huntingtin localization in brains of normal and Huntington's disease patients. Ann Neurol 1997; 42: 604-612.

21. Hirabayashi M, Inoue K, Tanaka K, Nakadate K, Ohsawa Y, Kamei Y et al. VCP/p97 in abnormal protein aggregates, cytoplasmic vacuoles, and cell death, phenotypes relevant to neurodegeneration. Cell Death Differ 2001; 8: 977-984.

22. Hsu YT, Youle RJ. Bax in murine thymus is a soluble monomeric protein that displays differential detergent-induced conformations. J Biol Chem 1998; 273: 10777-10783.

23. Nechushtan A, Smith CL, Hsu YT, Youle RJ. Conformation of the Bax C-terminus regulates subcellular location and cell death. EMBO J 1999; 18: 2330-2341.

24. Upton JP, Valentijn AJ, Zhang L, Gilmore AP. The N-terminal conformation of Bax regulates cell commitment to apoptosis. Cell Death Differ 2007; 14: 932-942.

25. Baur JA, Sinclair DA. Therapeutic potential of resveratrol: the in vivo evidence. Nat Rev Drug Discov 2006; 5: 493-506.
26. Xiang J, Chao DT, Korsmeyer SJ. BAX-induced cell death may not require interleukin 1 beta-converting enzyme-like proteases. Proc Natl Acad Sci USA 1996; 93: 14559-14563.

27. Zha H, Fisk HA, Yaffe MP, Mahajan N, Herman B, Reed JC. Structure-function comparisons of the proapoptotic protein Bax in yeast and mammalian cells. Mol Cell Biol 16; 1996: 6494-6508.

28. Jurgensmeier JM, Krajewski S, Armstrong RC, Wilson GM, Oltersdorf T, Fritz LC et al. Baxand Bak-induced cell death in the fission yeast Schizosaccharomyces pombe. Mol Biol Cell 1997; 8: 325-339.

29. Chou AH, Yeh TH, Kuo YL, Kao YC, Jou MJ, Hsu CY et al. Polyglutamine-expanded ataxin-3 activates mitochondrial apoptotic pathway by upregulating $\mathrm{Bax}$ and downregulating Bcl-xL. Neurobiol Dis 2006; 21: 333-345.

30. Wang HL, He CY, Chou AH, Yeh TH, Chen YL, Li AH. Polyglutamine-expanded ataxin-7 activates mitochondrial apoptotic pathway of cerebellar neurons by upregulating $B a x$ and downregulating Bcl-x(L). Cell Signal 2006; 18: 541-552.

31. Gama V, Yoshida T, Gomez JA, Basile DP, Mayo LD, Haas AL et al. Involvement of the ubiquitin pathway in decreasing Ku70 levels in response to drug-induced apoptosis. Exp Cell Res 2006; 312: 488-499.

32. Imai S, Armstrong CM, Kaeberlein M, Guarente L. Transcriptional silencing and longevity protein Sir2 is an NAD-dependent histone deacetylase. Nature 2000; 403: 795-800.

33. Parker JA, Arango M, Abderrahmane S, Lambert E, Tourette C, Catoire $\mathrm{H}$ et al. Resveratrol rescues mutant polyglutamine cytotoxicity in nematode and mammalian neurons. Nat Genet 2005; 37: 349-350.

34. McCampbell A, Taye AA, Whitty L, Penney E, Steffan JS, Fischbeck KH. Histone deacetylase inhibitors reduce polyglutamine toxicity. Proc Natl Acad Sci USA 2001; 98: 15179-15184

35. Minamiyama M, Katsuno M, Adachi $H$, Waza M, Sang $C$, Kobayashi $Y$ et al. Sodium butyrate ameliorates phenotypic expression in a transgenic mouse model of spinal and bulbar muscular atrophy. Hum Mol Genet 2004; 13: 1183-1192.

36. Saitoh M, Nishitoh H, Fujii M, Takeda K, Tobiume K, Sawada $Y$ et al. Mammalian thioredoxin is a direct inhibitor of apoptosis signal-regulating kinase (ASK) 1. EMBO J 1998; 17: 2596-2606.

\section{Supplementary Information accompanies the paper on Cell Death and Differentiation website (http://www.nature.com/cdd)}

